\title{
Proteomic and Metabolomic Analyses of Xylella fastidiosa OMV-Enriched Fractions Reveal Association with Virulence Factors and Signaling Molecules of the DSF Family
}

\author{
Oséias R. Feitosa-Junior, ${ }^{1}$ Eliezer Stefanello, ${ }^{1}$ Paulo A. Zaini, ${ }^{1,2}$ Rafael Nascimento, ${ }^{1,3}$ Paulo M. Pierry, ${ }^{1}$ \\ Abhaya M. Dandekar, ${ }^{2}$ Steven E. Lindow, ${ }^{4}$ and Aline M. da Silva ${ }^{1, \dagger}$ \\ ${ }^{1}$ Departamento de Bioquímica, Instituto de Química, Universidade de São Paulo, São Paulo, SP 05508-000, Brazil \\ ${ }^{2}$ Department of Plant Sciences, University of California, Davis, CA 95616, U.S.A. \\ ${ }^{3}$ Instituto de Genética e Bioquímica, Universidade Federal de Uberlândia, Uberlândia, MG 38400-902, Brazil \\ ${ }^{4}$ Department Plant and Microbial Biology, University of California, Berkeley, CA 94720, U.S.A.
}

Accepted for publication 8 April 2019.

\begin{abstract}
Xylella fastidiosa releases outer membrane vesicles (OMVs) known to play a role in the systemic dissemination of this pathogen. OMVs inhibit bacterial attachment to xylem wall and traffic lipases/esterases that act on the degradation of plant cell wall. Here, we extended the characterization of $X$. fastidiosa OMVs by identifying proteins and metabolites potentially associated with OMVs produced by Temecula1, a Pierce's disease strain, and by $9 \mathrm{a} 5 \mathrm{c}$ and $\mathrm{Fb} 7$, two citrus variegated chlorosis strains. These results strengthen that one of the OMVs multiple functions is to carry determinants of virulence, such as lipases/ esterases, adhesins, proteases, porins, and a pectin lyase-like protein.
\end{abstract}

ABSTRACT

For the first time, we show that the two citrus variegated chlorosis strains produce $X$. fastidiosa diffusible signaling factor 2 (DSF2) and citrus variegated chlorosis-DSF (likewise, Temecula1) and most importantly, that these compounds of the DSF (X. fastidiosa DSF) family are associated with OMV-enriched fractions. Altogether, our findings widen the potential functions of $X$. fastidiosa OMVs in intercellular signaling and host-pathogen interactions.

Keywords: citrus variegated chlorosis, diffusible signaling factor, outer membrane vesicle, Pierce's disease
Outer membrane vesicles (OMVs) are spherical particles of $\sim 30$ to $300 \mathrm{~nm}$ released into extracellular milieu by all Gram-negative bacteria studied (Jan 2017; Schwechheimer and Kuehn 2015). OMVs are currently considered an additional type of the bacterial secretion system (type 0 secretion system) that circumvents the arduous task of secreting compounds through the Gram-negative bacterial envelope (Guerrero-Mandujano et al. 2017). As a rule, the surface of OMVs reflects the bacterial outer membrane composition, including its phospholipids, membrane proteins, and lipopolysaccharides. The OMV lumen primarily contains periplasmic components trapped during the vesiculation process plus various metabolites, nucleic acids, and cytoplasmic and inner-membrane proteins (Jan 2017; Schwechheimer and Kuehn 2015; Toyofuku et al. 2019). OMVs have been proposed to traffic hydrophobic signaling molecules embedded in their lipid bilayer (Brameyer et al. 2018; Lynch and Alegado 2017).

\section{${ }^{\dagger}$ Corresponding author: A. M. da Silva; almsilva@iq.usp.br}

Funding: This research was funded by Conselho Nacional de Desenvolvimento Científico e Tecnológico (CNPq) grant 476656/2012-5, Coordenação de Aperfeiçoamento de Pessoal de Nível Superior (CAPES) grant 3385/2013, Fundação de Amparo à Pesquisa do Estado de São Paulo (FAPESP) grant 2008/11703-4, and the Pierce's Disease Control Program of the California Department of Food and Agriculture. O. R. Feitosa-Junior, R. Nascimento, and P. M. Pierry were supported by fellowships from the CAPES. P. M. Pierry was partially supported by FAPESP fellowship 2011/24091-0. A. M. da Silva acknowledges her research fellowship from the $\mathrm{CNPq}$

*The $e$-Xtra logo stands for "electronic extra" and indicates that six supplementary tables are published online.

The author(s) declare no conflict of interest.

(C) 2019 The American Phytopathological Society
OMVs can spread far from producer cells to perform functions in the environment, and their cargo, such as signaling molecules and virulence factors, would be duly protected from degradation until reaching the target site (Guerrero-Mandujano et al. 2017; Kulp and Kuehn 2010; Lynch and Alegado 2017). For instance, these bacterial secreted nanoparticles play key roles in cell signaling and quorum sensing (Brameyer et al. 2018; Mashburn and Whiteley 2005; Toyofuku et al. 2017), interspecies communication (Amano et al. 2010; Lynch and Alegado 2017), horizontal gene transfer (Fulsundar et al. 2014; Grull et al. 2018), nutrient acquisition ( $\mathrm{Li}$ et al. 2016), defense against environmental stressors (Volgers et al. 2018), antimicrobial activity (Kadurugamuwa and Beveridge 1996), and onset of metazoan immune response (Kaparakis-Liaskos and Ferrero 2015; Manning and Kuehn 2011; Pathirana and Kaparakis-Liaskos 2016).

Although the production of OMVs and their various related functions have been mostly investigated in animal pathogens, bacterial phytopathogens have been shown to release OMVs that participate in biofilm formation, virulence, and modulation of plant immunity (Katsir and Bahar 2017). For example, OMVs produced by Xanthomonas campestris pv. campestris (Sidhu et al. 2008; Solé et al. 2015) and Pseudomonas syringae pv. tomato (Chowdhury and Jagannadham 2013) contain virulence-associated proteins, such as protease, xylanase, and chitinase. Moreover, X. campestris pv. campestris and Xanthomonas oryzae pv. oryzae OMVs can induce typical immune responses in Arabidopsis thaliana (Bahar et al. 2014, 2016). In Xylella fastidiosa, OMVs function as antiadhesive nanoparticles, inhibiting bacterial attachment to plant cells and thus, facilitating the systemic dissemination of the phytopathogen (Ionescu et al. 2014).

$X$. fastidiosa OMVs have been shown to transport lipases/ esterases that degrade plant cell wall (Nascimento et al. 2016). Thus, as with other pathogenic bacteria (Toyofuku et al. 2019), $X$. fastidiosa may use OMVs to transport virulence factors. This seems to be quite relevant, because $X$. fastidiosa does not possess a type 3 secretion system (T3SS) (Van Sluys et al. 2002), which is 
commonly used by most phytopathogenic bacteria to secrete protein effectors that enhance virulence and/or suppress plant defenses (Büttner 2016). However, X. fastidiosa genome does encode the proteins required for assembly and function of type 1 secretion system (T1SS), type 2 secretion system (T2SS), and type 5 secretion system (T5SS) (Simpson et al. 2000; Van Sluys et al. 2003). Although T1SS seems to be important for detoxification of $X$. fastidiosa cells within the plant host (Reddy et al. 2007), its T2SS has been related to secretion of proteases and plant cell wall degrading enzymes (Rapicavoli et al. 2018). X. fastidiosa has six genes predicted to encode autotransporters from the T5SS family, one of which is the adhesin XatA (Matsumoto et al. 2012). In addition, three other genes encoding trimeric autotransporters from the T5SS family are found in X. fastidiosa genome, two of each are known as the afimbrial adhesins XadA1 and XadA2 (Caserta et al. 2010). A complete type 4 secretion system (T4SS) involved in conjugation and DNA transfer among bacteria is encoded in some $X$. fastidiosa plasmids (Burbank and Van Horn 2017). Although, homologous genes of the plasmidial T4SS are also found in the chromosome of X. fastidiosa (Marques et al. 2001; Simpson et al. 2000), currently nothing is known regarding their function.

Expressions of several of the virulence and/or pathogenicity determinants in $X$. fastidiosa are regulated by a signaling pathway mediated by $X$. fastidiosa diffusible signaling factor (DSF) (Chatterjee et al. 2008; Wang et al. 2012). X. fastidiosa DSF comprises a family of related unsaturated fatty acids (Ionescu et al. 2016) that regulates bacterial behavior in a cell density-dependent manner, modulating the transition from less adhesive and motile phenotype to more adhesive sessile cells. Although the motile phenotype is critical for systemic plant colonization, the adherent cells form a biofilm both in the insect vectors and in the xylem (Chatterjee et al. 2008). Regulation of pathogenicity factors (rpf) genes is responsible for production and sensing of $X$. fastidiosa DSF (Chatterjee et al. 2008). Accordingly, a mutant blocked in production of $X$. fastidiosa DSF $(\Delta r p f \mathrm{~F})$ has a less adhesive phenotype, is hypervirulent to plant host, and is impaired in insect colonization and transmission (Ionescu et al. 2013; Newman et al. 2004).

$X$. fastidiosa is receiving an increasing attention since it reemerged as a plant pathogen of global importance. Once confined to the Americas, this pathogen is spreading throughout Europe (Sicard et al. 2018). This bacterium is transmitted by ubiquitous generalists xylem sap-feeding insects (Almeida and Nunney 2015; Redak et al. 2004), being the causative agent of several important crop diseases (Janse and Obradovic 2010; Rapicavoli et al. 2018), such as the Pierce's disease (PD) of grapevine (Hopkins and Purcell 2002), the citrus variegated chlorosis (CVC) of orange tree ( $\mathrm{Li} \mathrm{et} \mathrm{al.}$ 1999), and the quick decline syndrome of olive tree (Cariddi et al. 2014; Della Coletta et al. 2016).

In this study, we extended the characterization of $X$. fastidiosa OMVs by analyzing the protein and lipid composition of OMVs produced by three different strains, one of them associated with PD (strain Temecula1) and two of them associated with CVC (strains $9 \mathrm{a} 5 \mathrm{c}$ and $\mathrm{Fb} 7)$. Our results show, for the first time, that, other than several virulence-related proteins, $X$. fastidios $a$ OMVs also seem to traffic $X$. fastidiosa DSF, thus expanding our understanding of the functions played by this secretion mechanism in host colonization, virulence, and onset of plant diseases.

\section{MATERIALS AND METHODS}

$X$. fastidiosa strains and growth conditions. $X$. fastidiosa PD strain Temecula1 (Newman et al. 2003; Van Sluys et al. 2003) and the CVC strains 9a5c (Li et al. 1999; Simpson et al. 2000) and Fb7 (da Silva et al. 2007) were routinely cultured for 5 to 7 days in periwinkle wilt glucose (PWG) agar medium, which is periwinkle wilt (PW) medium (Davis et al. 1981) plus $0.5 \%$ glucose. To obtain liquid bacterial cultures, cells were harvested from the agar plates and inoculated in PWG broth (filtered through $0.22-\mu \mathrm{m}$ membrane) with optical densities at $600 \mathrm{~nm}\left(\mathrm{OD}_{600}\right)$ of 0.05 to 0.1 . Cultures were maintained for 7 days at $28^{\circ} \mathrm{C}$ in a rotary shaker at 100 rotations per minute until they reached an $\mathrm{OD}_{600}$ of 0.8 to 1.2. Total protein content of bacterial cultures was determined using Bradford reagent (Bio-Rad Laboratories, Inc.).

Nanoparticle tracking analysis of cell-free culture supernatants. Concentration and size distribution of nanoparticles in $X$. fastidiosa culture supernatants were determined by nanoparticle tracking analysis (NTA) using a NanoSight LM10 system (NanoSight Ltd.) following a previously described procedure (Ionescu et al. 2014). Briefly, cells were removed by two cycles of centrifugation at $16,000 \times g$ for $20 \mathrm{~min}$ each at $4^{\circ} \mathrm{C}$, and the cell-free culture supernatant was carefully removed and kept on ice. Each sample, in triplicate, was diluted in $0.22-\mu \mathrm{m}$ filtered phosphate buffered saline (PBS) $\left(\mathrm{pH}\right.$ 7.4) to a concentration of $10^{8}$ to $10^{9}$ particles per milliliter and loaded in the NanoSight equipment. A monochromatic laser beam at $405 \mathrm{~nm}$ was applied, and three videos of $30 \mathrm{~s}$ were recorded, with sample mixing between recordings. Camera sensitivity and detection threshold were set to 14 . Ambient temperature ranged from 20 to $22^{\circ} \mathrm{C}$. The videos were analyzed using the NTA software (version 2.3), with the parameters minimal expected particle size, minimum track length, and blur setting all set to automatic. NanoSight particle analysis from PWG medium (blank sample) was subtracted from each sample measurement (Turner et al. 2018). NTA was performed in three biological replicates (three independent cultures) of each $X$. fastidiosa strain, and the average was calculated and plotted as particle size versus number of particles per milliliter. Statistically significant differences on nanoparticles counting between the different strains were determined with the Fisher's least significant difference (LSD) test.

Preparation of OMV-enriched fraction. OMVs enrichment from $X$. fastidiosa culture supernatants was performed using sequential centrifugation as previously described (Ionescu et al. 2014; Matsumoto et al. 2012) from three independent cultures for each strain. Briefly, $X$. fastidiosa cells were pelleted from $400 \mathrm{ml}$ cultures by centrifugation at $8,000 \times g$ for $15 \mathrm{~min}$ at $4^{\circ} \mathrm{C}$. The cellfree culture supernatant was carefully collected and centrifuged at $38,000 \times g$ for $1 \mathrm{~h}$ at $4^{\circ} \mathrm{C}$ in a P28S rotor (Hitachi) to remove cell debris. The $38,000 \times g$ supernatant was collected and centrifuged at $144,000 \times g$ for $5 \mathrm{~h}$ at $4^{\circ} \mathrm{C}(\mathrm{P} 28 \mathrm{~S}$ rotor; Hitachi). The high-speed centrifugation pellets enriched in OMVs were immediately processed for scanning electron microscopy, shotgun proteomics, and metabolomics.

Scanning electron microscopy. The OMV-enriched fraction suspended in PBS (pH 7.4) was spotted on glass coverslips and fixed with $10 \%$ glutaraldehyde solution in PBS (pH 7.4) in 24-well plates. Next, the samples were gently immersed in $1 \%$ osmium tetroxide buffer for $1 \mathrm{~h}$, washed three times with cacodylate buffer, treated with $1 \%$ tannic acid for $30 \mathrm{~min}$, and washed twice with deionized water. Then, the samples were impregnated with osmium tetroxide for $30 \mathrm{~min}$, rinsed for three times with deionized water, and gradually dehydrated with ethanol concentrations starting at $50 \%$ for $10 \mathrm{~min}$, with $10 \%$ increments every time. After critical point drying, samples were coated with a layer of 25- to 50-nm gold and kept dehydrated until analyzed in a scanning electron microscope model FEI Quanta 250 FEG operating at 20 to $30 \mathrm{kV}$.

Label-free shotgun proteomics. Three independent OMVenriched preparations (pellet after high-speed ultracentrifugation) for each $X$. fastidiosa strain were suspended in $8 \mathrm{M}$ urea buffer containing protease inhibitors (cOmplete; Roche). Next, they were pooled, concentrated by freeze drying, and kept dried at room temperature until the shotgun proteomic analysis. The dried samples were reconstituted in PBS, and $300 \mu \mathrm{g}$ of each sample was precipitated with four times the volume of ProteoExtract Protein Precipitation Kit (Calbiochem) according to the manufacturer's instructions. The samples were reconstituted in $100 \mu \mathrm{l}$ of $6 \mathrm{M}$ urea in $50 \mathrm{mM}$ triethylammonium bicarbonate (TEAB) plus $5 \mathrm{mM}$ dithiothreitol (DTT) and incubated at $37^{\circ} \mathrm{C}$ for $30 \mathrm{~min}$ with 1,000 rpm shaking. Next, $15 \mathrm{mM}$ iodoacetoamide (IAA) was added 
followed by incubation at room temperature for $30 \mathrm{~min}$. The IAA was then neutralized with $30 \mathrm{mM}$ DTT in incubation for $10 \mathrm{~min}$. Lys-C/trypsin was added (1:25 enzyme/total protein) followed by incubation at $37^{\circ} \mathrm{C}$ for $4 \mathrm{~h}$. TEAB $(550 \mu \mathrm{l}$ of $50 \mathrm{mM})$ was added to dilute the urea and activate trypsin digestion overnight. The digested peptides were desalted with Aspire RP30 Desalting Tips (Thermo Scientific), vacuum dried, and suspended in $45 \mu \mathrm{l}$ of $50 \mathrm{mM}$ TEAB. Peptides were quantified by Pierce quantitative fluorometric assay (Thermo Scientific), and $1 \mu \mathrm{g}$ was analyzed on a QExactive mass spectrometer (Thermo Scientific) coupled with an Easy-LC source (Thermo Scientific) and a nanospray ionization

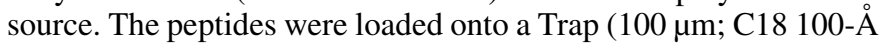
$5 \mathrm{U})$ and desalted online before separation using a reversed-phase (75 $\mu \mathrm{m}$; C18 200- $\AA 3 \mathrm{U}$ ) column. The duration of the peptide separation gradient was 60 min using $0.1 \%$ formic acid and $100 \%$ acetonitrile ( $\mathrm{ACN}$ ) for solvents $\mathrm{A}$ and $\mathrm{B}$, respectively. The data were acquired using a data-dependent MS/MS (tandem mass spectrometry) method, which had a full scan range of 300 to $1,600 \mathrm{Da}$ and a resolution of 70,000. The resolution of the MS/MS method was 17,500, and the insulation width was $2 \mathrm{~m} / \mathrm{z}$, with normalized collision energy of 27 . The nanospray source was operated using a spray voltage of $2.2 \mathrm{kV}$ and a transfer capillary temperature heated to $250^{\circ} \mathrm{C}$.

The raw data were analyzed using $\mathrm{X}$ ! Tandem and viewed using the Scaffold Software v.4. (Proteome Software, Inc.). Samples were searched against UniProt databases appended with the cRAP database, which recognizes common laboratory contaminants. Reverse decoy databases were also applied to the database before the $\mathrm{X}$ ! Tandem searches. The coding sequences (CDSs) annotated in the genomes of the Temecula1 and 9a5c strains were used as reference for identification of the proteins at their respective proteomes. The 9a5c strain genome was used as a reference for $\mathrm{Fb} 7$ strain. The proteins identified were filtered in the Scaffold software based on the following criteria: $1.0 \%$ false discovery rate (FDR) at protein level (following the prophet algorithm: http://proteinprophet.sourceforge.net/), minimum number of two peptides, and $0.1 \%$ FDR at peptide level. Proteins sequences identified were examined for the presence of a signal peptide (Petersen et al. 2011) and the potential (SecP score) of being secreted by a nonclassical protein secretion system (Bendtsen et al. 2005).

Metabolomics. For metabolome analysis, three independent OMV-enriched preparations for each X. fastidiosa strain were pooled and dried in an Eppendorf Concentrator 5301. Methanol was then added to the precipitate, and the suspension was centrifuged for $5 \mathrm{~min}$ at $12,000 \times g$ followed by filtration in a $0.45-\mu \mathrm{m}$ PVDF (polyvinylidene difluoride) membrane. The samples were then injected into the Shimadzu UFLC-20AD chromatograph coupled to a Bruker TOF mass spectrometer. The suspension was separated with a Phenomenex Kinetex C18 $100 \times 2.1 \mathrm{~mm}$ with 2.6- $\mu \mathrm{m}$ particle size and $100-\AA$ pore size. Mobile phase $\mathrm{A}$ consisted of $10 \mathrm{mM} \mathrm{NH}_{4} \mathrm{Ac}$ in water ( $\mathrm{pH} \mathrm{8)}$ ), and mobile phase B consisted of $95 \% \mathrm{ACN}+5 \%$ mobile phase solution A. Binary gradient program was 0 to $1 \mathrm{~min}, 5 \% ; 1$ to $12 \mathrm{~min}, 40 \% ; 12$ to $18 \mathrm{~min}, 80 \%$; 18 to $20 \mathrm{~min}, 80 \%$; 20 to $21 \mathrm{~min}, 5 \%$; and 21 to $24 \mathrm{~min}, 5 \%$. Flow was set at $400 \mu \mathrm{l}$, and oven temperature was maintained at $40^{\circ} \mathrm{C}$. Mass spectrometer parameters were used as follows: negative mode, $-3,800 \mathrm{~V}$; offset, $500 \mathrm{~V}$; gas temperature, $250^{\circ} \mathrm{C}$; 10 liters/min; scan range, 50 to $1,000 \mathrm{~m} / \mathrm{z}$; and scan rate, $1 \mathrm{~Hz} / \mathrm{s}$. The compounds that had their molecular masses resolved were identified, and their identities were predicted with ProbMetab software (Silva et al. 2014) and the KEGG database (https://www.kegg.jp/) for the X. fastidiosa metabolic model inferred from its complete genome. Methanol solutions of synthetic 2-cis-tetradecenoic acid (X. fastidiosa DSF1), 12methyltetradecanoic (CVC-DSF), 2-cis-hexadecenoic acid (X. fastidiosa DSF2), and octadecanoic acid (C18:0) (Beaulieu et al. 2013) were run as standards. Both the OMV extracts and synthetic standards were compared with a blank sample (PWG medium), which was extracted as described above.

\section{RESULTS}

X. fastidiosa CVC strains release OMVs. $X$. fastidiosa PD strain Temecula1 has been shown to release OMVs in culture supernatants (Ionescu et al. 2014; Matsumoto et al. 2012; Nascimento et al. 2016) and in the xylem (Ionescu et al. 2014). The number and size distribution of nanoparticles, which include OMVs, in culture supernatants of $X$. fastidiosa strains were estimated by NTA. After 7 days of culture in PWG, the CVC strains $9 \mathrm{a} 5 \mathrm{c}$ and $\mathrm{Fb} 7$ released nanoparticles $\left(1\right.$ to $\left.3 \times 10^{8} / \mathrm{ml}\right)$ with average size of $100 \mathrm{~nm}$, similar to Temecula1 (Fig. 1A). The three strains presented comparable cell densities and total protein content (Fig. 1B), but strain Fb7 exhibited 60\% higher nanoparticles count per $1 \mathrm{ml}(P<0.05$ in Fisher's LSD test $)$ than strains 9a5c and Temecula1 (Fig. 1A). Given the remarkably adhesive phenotype of 9a5c strain and the mucoid-like phenotype of Fb7, CFU assessments
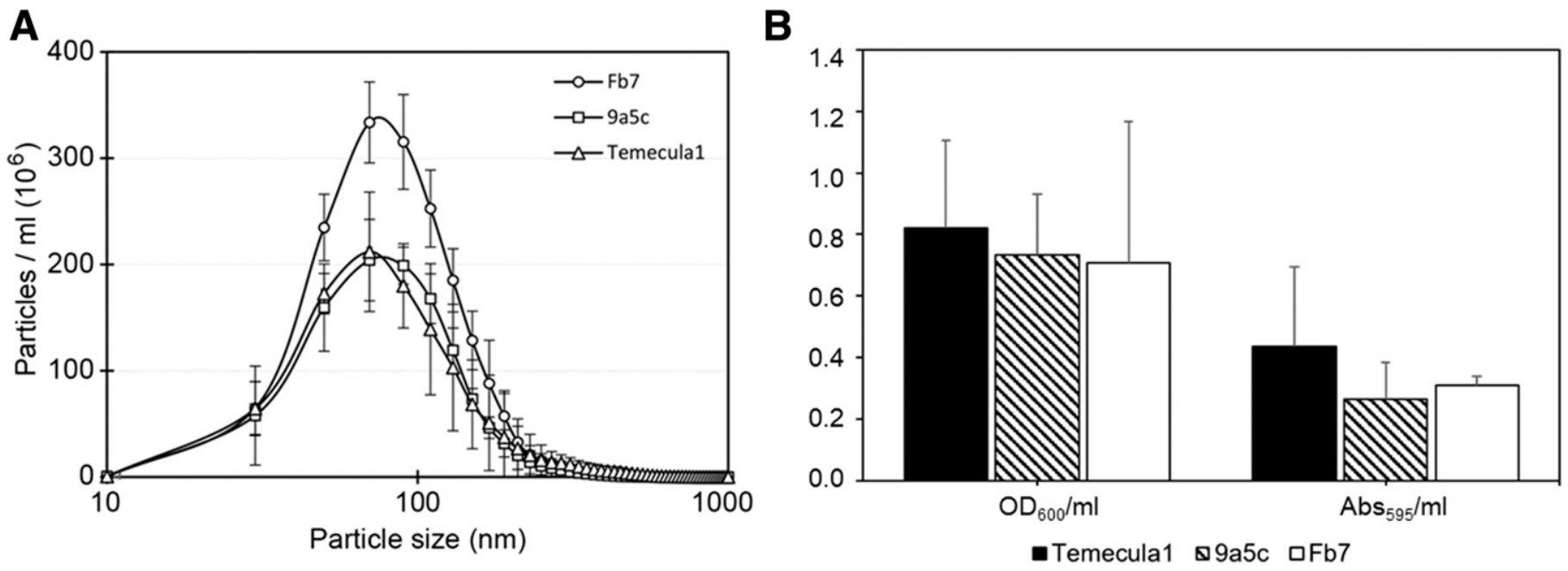

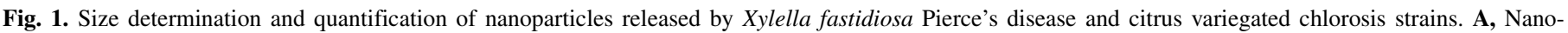

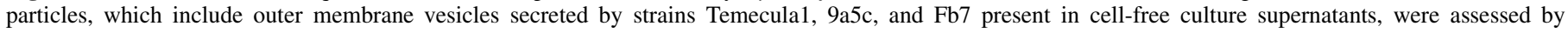

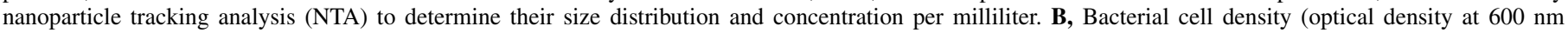

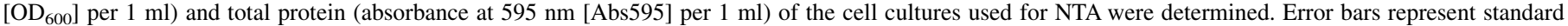
deviation of the mean of three biological replicates, with three technical replicates each. 
were not reliable for these two strains, and as such, it was not possible to determine their nanoparticle production per cell number. However, Temecula1 produced $170 \pm 79$ nanoparticles per CFU after 7 days growth in PWG medium, which is approximately three times more than previously observed $(51 \pm 20$ nanoparticles per CFU) after 4 days of growth in Pierce's disease 3 (PD3) medium (Ionescu et al. 2014). Although NTA does not identify the type of the nanoparticle material in the cell-free culture supernatants, the detected nanoparticles are known to include OMVs (Chan et al. 2017; Ionescu et al. 2014).

To further investigate the production of OMVs by Temecula1, 9a5c, and $\mathrm{Fb} 7$ strains, OMV-enriched preparations were evaluated by scanning electron microscopy (Fig. 2A to F). No detectable variations in form and size range of these nanoparticles among the different strains were seen in culture suspensions (Fig. 2G to I).
$X$. fastidiosa OMVs carry porins, adhesins, and hydrolases. Using label-free shotgun proteomics, we identified a large set of proteins potentially associated with the OMVs secreted by Temecula1 and two CVC strains (9a5c and Fb7) (Supplementary Tables S1, S2, and S3). This approach identified, with a high degree of confidence (1.0\% FDR at the protein level), 122, 152, and $122 \mathrm{OMV}$-associated proteins for Temecula1, 9a5c, and $\mathrm{Fb} 7$, respectively. These were then ranked based on their relative abundances according to Scaffold software quantitation (Scaffold score). Among the potentially OMV-associated proteins, we have identified that 65,72 , and $79 \%$ are predicted as secreted proteins in strains Temecula1, 9a5c, and Fb7, respectively, based on signal peptide analysis and the SecP score. Moreover, about onethird of the identified proteins are predicted to be located on the outer membrane. Indeed, several of the identified proteins are

\section{Temecula1}
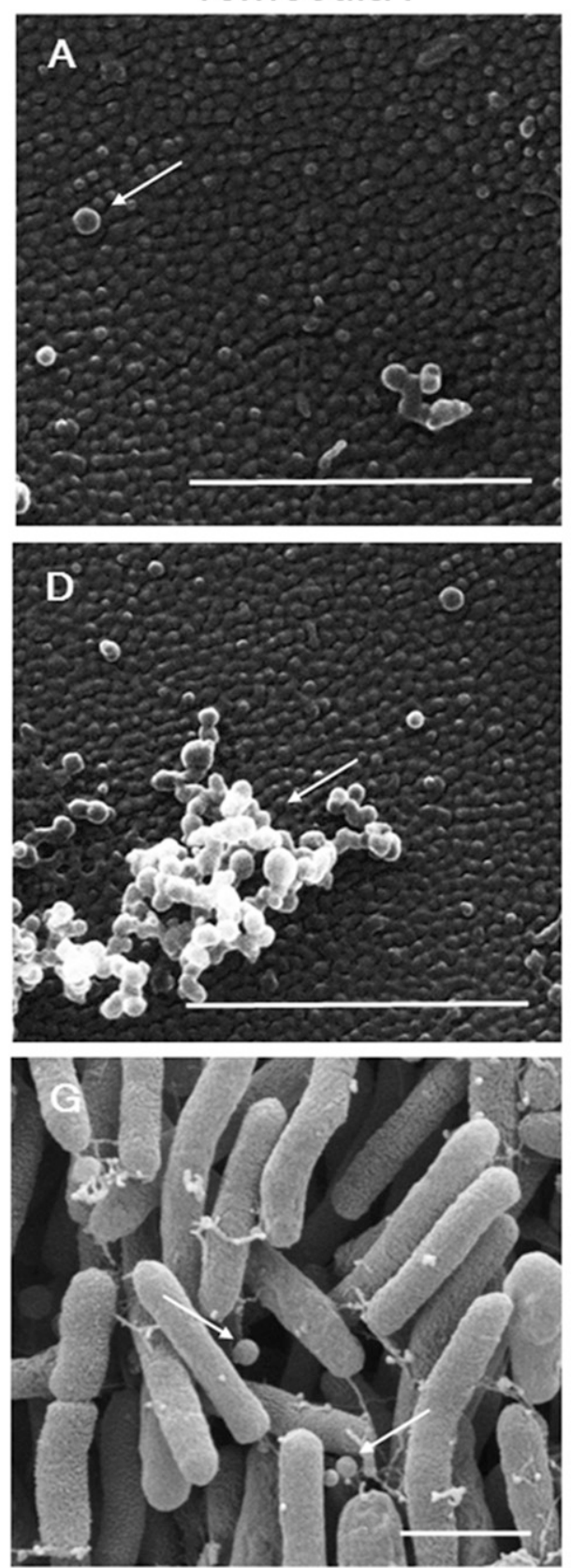

$9 a 5 c$
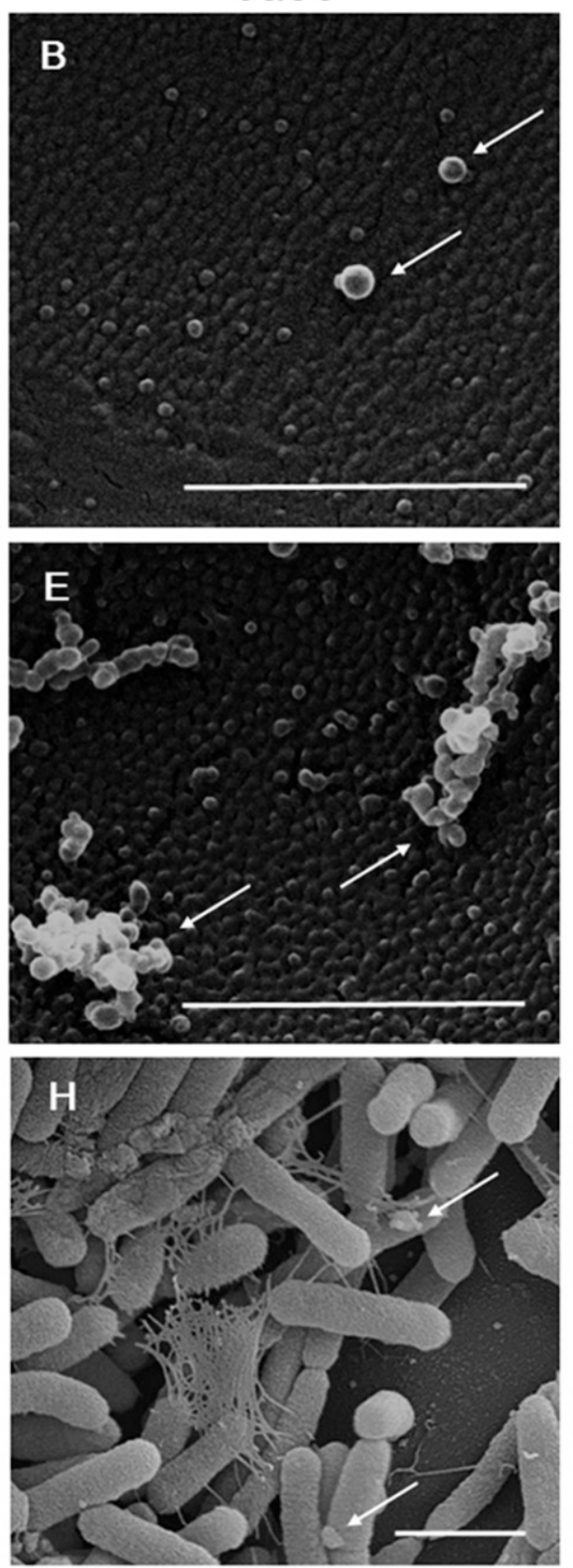

$\mathrm{Fb7}$
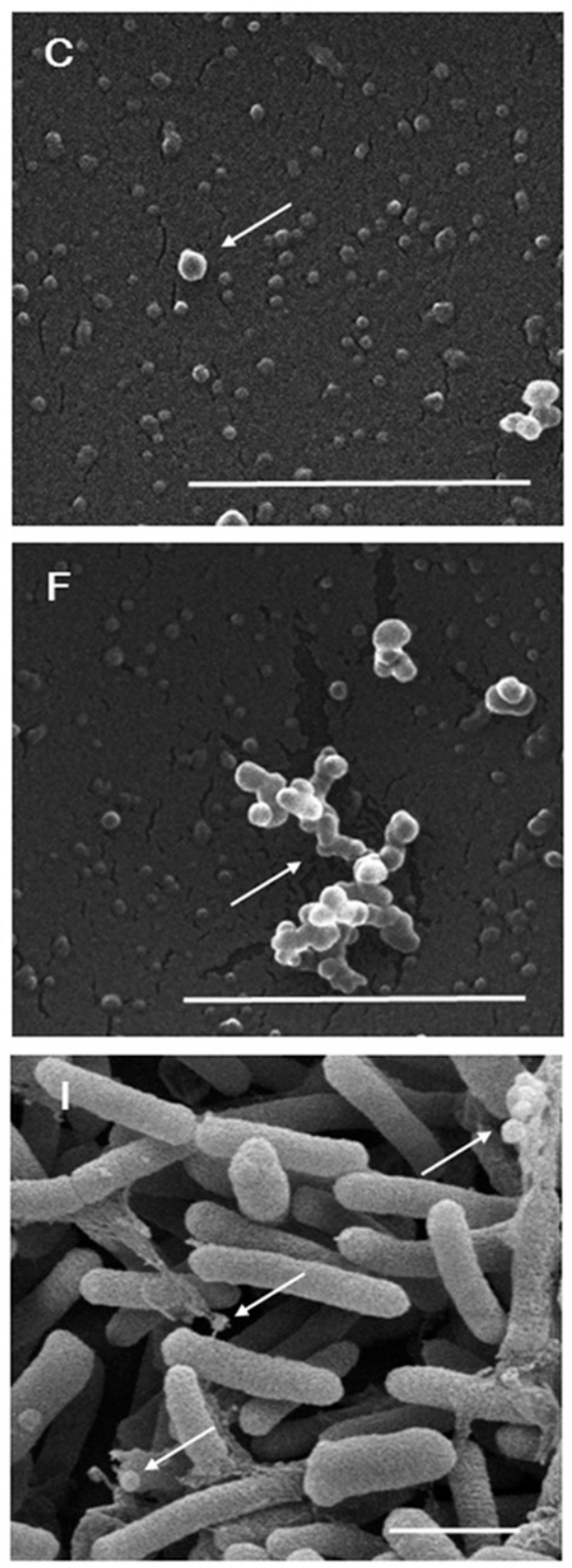

Fig. 2. Electron scanning micrographs of outer membrane vesicles (OMVs) from strains Temecula1, 9a5c, and Fb7. A to F, OMV preparations from culture supernatants. A to $\mathbf{C}$, Isolated OMVs or $\mathbf{D}$ to $\mathbf{F}$, clusters of OMVs are shown. $\mathbf{G}$ to I, OMVs associated with cells. A, D, and G, Strain Temecula1. B, E, and $\mathbf{H}$, Strain 9a5c. C, F, and I, Strain Fb7. Scale bars $=1 \mu \mathrm{m}$. 
well-known outer membrane proteins, such as OmpW, OmpA, MopB, PorinO, TonB-dependent receptor, and XadA1 (Nascimento et al. 2016).

Of the 199 unique proteins detected in the OMV-enriched preparations, 67 were shared by the three strains (Fig. 3A), whereas 26,31 , and 12 proteins seemed to be exclusive to strains Temecula1, $9 \mathrm{a} 5 \mathrm{c}$, and $\mathrm{Fb} 7$, respectively. The 35 most abundant proteins identified in the OMV-enriched fraction for each one of three $X$. fastidiosa strains comprise 58 unique proteins (Table 1). The three strains share 45 of these 58 proteins (Fig. 3B), although there is a great variation in their abundances indicated by the ranking positions in each strain's OMV proteome (Table 1). Ten of the 45 shared top abundant proteins (Table 1) were already found to be OMV associated as well as soluble proteins in Temeculal culture supernatant (Nascimento et al. 2016).

The OMVs of the three strains have in common the afimbrial adhesins XadA1, Hsf/XadA2, and XadA3 but with great variation in their relative abundances. Although XadA1 seems relatively more abundant than XadA3 in Temecula1 and Fb7, the opposite situation is verified for 9a5c (Table 1). Another protein also common to all three strains is Omp1X (PD1063), heretofore known as Ax21, which was previously reported to be OMV associated (Pierce et al. 2014). The OMV-enriched fraction of the three strains also contains the autotransporter XatA1 (PD0528), previously described to be OMV associated in Temecula1 (Matsumoto et al. 2012). Up to six distinct porins were detected on OMVs-enriched fractions of the three strains.

Several hydrolases (lipases/esterases, proteases, and peptidases) were also detected, with lipases/esterases LesA (PD1702/XF0357) and LesB (PD1703/XF0358) among the most abundant in the OMV proteome (Table 1). Although in lower abundance, we highlight the identification of the XF0119/PD0090 protein in the OMV-enriched preparations of the three strains. This CDS encodes a domain characteristic of pectin lyases and has $31 \%$ sequence similarity to a $X$. oryzae pectate lyase (data not shown).

Among the selected proteins listed in Table 1, just a few seem to be exclusive to one or two strains (Fig. 3B). We highlight the BamA protein (XF1046) and the XF1496 TonB-dependent receptor that were detected only in the OMVs of the citrus strains (Fb7 and 9a5c). However, the CDS annotated as L-ascorbate oxidase (XF2677/ PD2039) was detected in the OMV-enriched proteome of $\mathrm{Fb} 7$ and Temecula1 strains but not in 9a5c (Table 1).

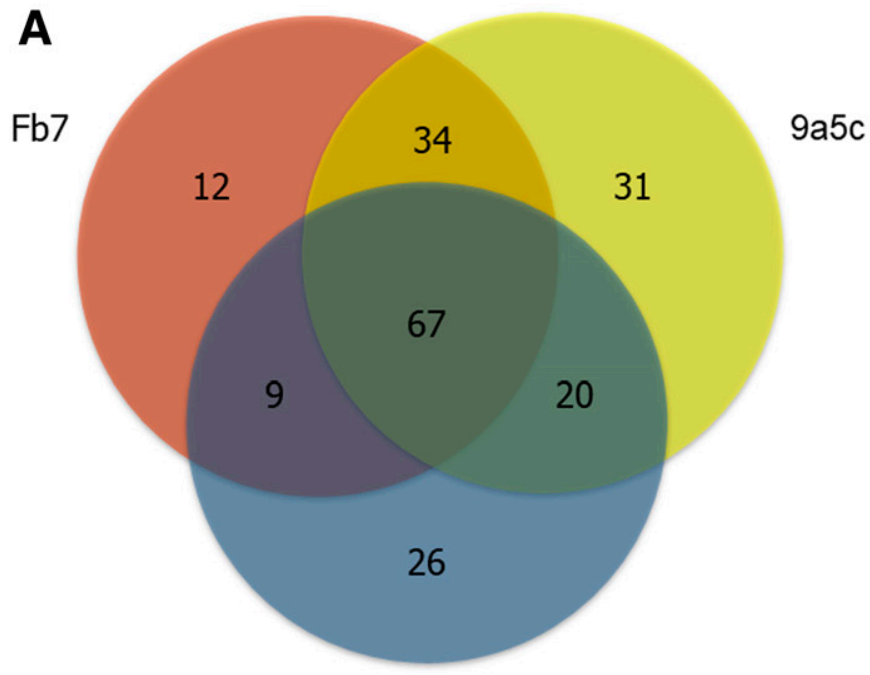

Temecula1
Although hemagglutinin PspA (XF2775/PD2118; HxfA) was detected in Temecula1 OMVs, a paralogous hemagglutinin (XF0889/PD1792; HxfB) was found in the OMVs of strain 9a5c. However, none of the two hemagglutinins were found in the OMVs of $\mathrm{Fb} 7$, a strain that presents a mucoid-like phenotype (unpublished observation).

$X$. fastidiosa OMVs carry $X$. fastidiosa DSF2 and CVCDSF. Aiming to complement the characterization of OMVs composition, we performed an untargeted metabolomics approach using mass spectrometry. Approximately 275 compounds from an OMV-enriched fraction of strains Temecula1, 9a5c, and Fb7 had their molecular masses resolved, and their identities were predicted using ProbMetab and the KEGG database. The list of likely metabolites predicted in $X$. fastidiosa OMV-enriched fraction includes fatty acids, free amino acids, carbohydrates, and phenolic compounds (Supplementary Tables S4, S5, and S6). For the purpose of this work, however, we focused our attention on the fatty acid content of the OMVs, particularly those of the $X$. fastidiosa DSF family (Beaulieu et al. 2013; Colnaghi Simionato et al. 2007; Ionescu et al. 2016).

Our metabolome analysis of Temecula1, 9a5c, and Fb7 OMVenriched fractions indicated that all three strains produce CVCDSF, $X$. fastidiosa DSF2 (C16:1), and C18:0, the identities of which were further confirmed by comparative analysis with synthetic standards (Fig. 4). These results show, for the first time, that the two CVC strains produce $X$. fastidiosa DSF2 and CVC-DSF (likewise Temecula1) and most importantly, that these compounds were found in association with OMVs. However, X. fastidiosa DSF1 (C14:1) was not detected in either of the OMVs-enriched fractions from the three $X$. fastidiosa strains.

\section{DISCUSSION}

Initially suggested as artifacts of bacterial growth, OMVs have a plethora of functions demonstrated in intraspecies and interspecies cell-cell communication, mediating pathogenesis as well as beneficial ecological interactions (Kulp and Kuehn 2010; Lynch and Alegado 2017; Pathirana and Kaparakis-Liaskos 2016; Schwechheimer and Kuehn 2015; Toyofuku et al. 2019). Although somewhat underappreciated, the implications of OMVs released by bacterial plant pathogens for host colonization have begun to be unraveled (Chowdhury and Jagannadham 2013; Katsir and Bahar

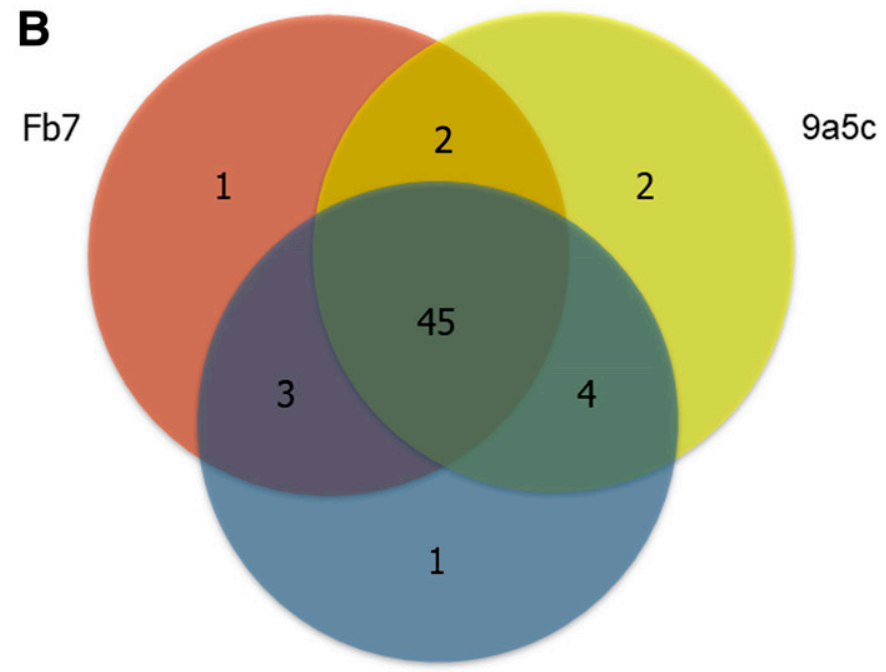

Temecula1

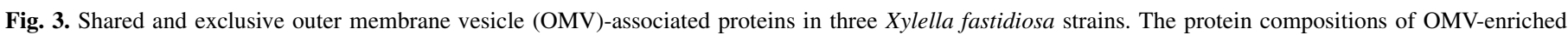

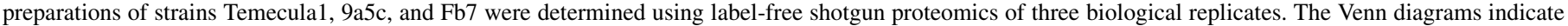

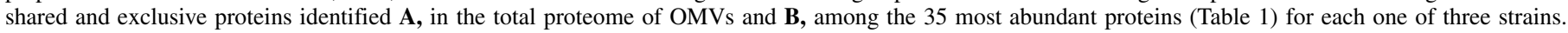


2017; Sidhu et al. 2008). For instance, $X$. fastidiosa OMVs seem to facilitate systemic dispersal of bacterial cells in the plant host, increasing virulence (Ionescu et al. 2014) and traffic lipases/ esterases that have the potential to act on the degradation of plant cell wall in sites distant from OMV-producing cells (Nascimento et al. 2016).

The work reported here further explores the importance and complexity of OMVs in $X$. fastidiosa by expanding the set of proteins potentially associated with native OMVs produced by one
PD and two CVC wild-type strains and determining the metabolites predicted in OMVs-enriched fractions. It is worth mentioning that we did not apply any intervention to increase OMV production. Enhancement of vesiculation by a variety of external stimuli can improve OMV yield but may change the composition of native OMVs (Klimentová and Stulik 2015). Thus, for the purpose of this work, we followed previously described protocols to obtain native OMV-enriched preparations by using sequential centrifugation (Gasperini et al. 2018; Ionescu et al. 2014; Kulp et al. 2015; Mantri

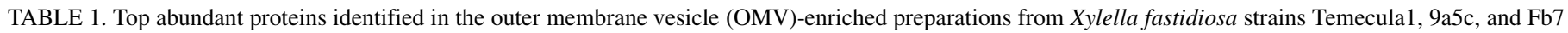

\begin{tabular}{|c|c|c|c|c|c|c|}
\hline \multirow[b]{2}{*}{ CDS number ${ }_{\mathrm{CVC}}$} & \multirow[b]{2}{*}{ CDS number ${ }_{\mathrm{PD}}{ }^{\mathrm{a}}$} & \multirow[b]{2}{*}{ CDS symbol } & \multirow[b]{2}{*}{ Gene product } & \multicolumn{3}{|c|}{ Ranking (scaffold score) } \\
\hline & & & & Temecula1 & $9 \mathrm{a} 5 \mathrm{c}$ & $\mathrm{Fb} 7$ \\
\hline XF0357 & PD1702 & LesA & Lipase/Esterase LesA & 1 & 14 & 7 \\
\hline XF0358 & PD1703 & LesB & Lipase/Esterase LesB & 2 & 24 & 11 \\
\hline XF0872 & PD1807 & OmpW & Outer membrane protein $\mathrm{W}$ & 3 & 52 & 1 \\
\hline XF1026 & PD0313 & PspB & Serine Protease PspB & 4 & 1 & 45 \\
\hline XF1516 & PD0731 & XadA1 & Adhesin XadA1 & 5 & 61 & 2 \\
\hline XF0343 & PD1709 & OmpA/mopB & Outer membrane protein $\mathrm{A}$ & 6 & 2 & 9 \\
\hline XF1036 & PD0318 & & Porin & 7 & 12 & 3 \\
\hline XF2237 & PD1283 & & TonB-dependent receptor & 8 & 4 & 4 \\
\hline XF1851 & PD0950 & & Serine protease & 9 & 11 & 19 \\
\hline XF0363 & PD1699 & & Peptidoglycan-associated lipoprotein & 10 & 7 & 13 \\
\hline XF1547 & PD0757 & Lpp & Membrane lipoprotein Lpp & 11 & 18 & 23 \\
\hline XF1981 & PD0824 & XadA3 & Adhesin XadA3 & 12 & 3 & 20 \\
\hline XF2713 & PD2065 & CirA & Porin CirA & 13 & 5 & 8 \\
\hline XF0975 & PD0270 & OprP & Porin O OprP & 14 & 9 & 10 \\
\hline XF2586 & PD1964 & TolC & Outer membrane TolC & 15 & 8 & 6 \\
\hline XF2775 & PD2118 & PspA & Hemagglutinin PspA & 16 & - & - \\
\hline XF0550 & PD1589 & BtuB & Porin BtuB & 17 & 10 & 36 \\
\hline XF1529 & PD0744 & XadA2/Hsf & Adhesin XadA2/Hsf & 18 & 152 & 64 \\
\hline XF1226 & PD0503 & & Protein of unknown function & 19 & 31 & 55 \\
\hline XF0083 & PD0062 & FimA & Fimbrial protein FimA & 20 & 36 & - \\
\hline XF2407 & PD1427 & RTX & Hemolysin toxin protein RTX & 21 & 35 & 94 \\
\hline XF2628 & PD1996 & EF-Tu & Elongation factor-Tu & 22 & 39 & - \\
\hline XF0339 & PD1711 & & TonB-dependent receptor & 23 & 32 & 14 \\
\hline XF1287 & PD0540 & & Protein of unknown function & 24 & 13 & 5 \\
\hline XF2137 & PD1200 & BfeA & Ferric enterobactin receptor $\mathrm{Bfe} A$ & 25 & 118 & 40 \\
\hline XF0081 & PD0060 & FimD & Outer membrane protein FimD & 26 & 20 & - \\
\hline XF0531 & PD0956 & & Cysteine/serine peptidase & 27 & 74 & 30 \\
\hline XF0668 & PD1506 & RTX & Hemolysin toxin protein RTX & 28 & 17 & 109 \\
\hline XF1827 & PD1040 & OsmC/OhrA & Hydroperoxide reductase OsmC/OhrA & 29 & 79 & 108 \\
\hline XF0898 & PD1786 & & Membrane lipoprotein & 30 & 29 & 104 \\
\hline XF2349 & PD0528 & & Autotransporter beta-domain (XatA1) & 31 & 16 & 68 \\
\hline XF1803 & PD1063 & & Omp1X & 32 & 6 & 26 \\
\hline XF0820 & PD1850 & & Zn-dependent amino- or carboxypeptidase & 33 & 90 & 58 \\
\hline XF2677 & PD2039 & Aoo & L-ascorbate oxidase Aoo & 34 & - & 12 \\
\hline XF1811 & PD1055 & Slp & Outer membrane protein Slp & 35 & 40 & 21 \\
\hline XF0395 & PD1672 & $\mathrm{Bfr}$ & Bacterioferritin Bfr & 37 & 65 & 33 \\
\hline XF2151 & PD1211 & LesC & Lipase/Esterase LesC & 40 & 147 & 15 \\
\hline XF0615 & PD1538 & GroL & Chaperonin GroL & 41 & 30 & 116 \\
\hline XF1896 & PD0895 & OmpA & Outer membrane protein $\mathrm{A}$ & 44 & 33 & 17 \\
\hline XF1911 & PD0880 & & Membrane lipoprotein & 46 & 34 & 24 \\
\hline XF0321 & PD0264 & OprO & Porin O OprO & 47 & 22 & 77 \\
\hline XF1887 & PD0904 & & Cysteine/serine peptidase PS-46 & 50 & 19 & 32 \\
\hline XF1897 & PD0894 & TolB & TolB protein & 51 & 23 & 16 \\
\hline XF0781 & PD1879 & EstA & Lipase/Esterase & 52 & 43 & 22 \\
\hline XF0816 & PD1853 & & $\mathrm{Zn}$-dependent peptidase & 53 & 44 & 29 \\
\hline XF1434 & PD0955 & & Cysteine/serine peptidase & 54 & 109 & 27 \\
\hline XF0855 & PD1820 & NlpD & Lipoprotein NlpD & 60 & 27 & 47 \\
\hline XF0464 & PD1620 & BamB & Outer membrane protein BamB & 62 & 38 & 35 \\
\hline XF2349 & PD1379 & & Autotransporter beta-domain & 63 & 16 & 68 \\
\hline XF1628 & PD1151 & YdiY & Outer membrane protein YdiY & 123 & 28 & 53 \\
\hline XF1577 & PD0978 & & DUF2184 & - & 15 & - \\
\hline XF1011 & PD0305 & RTX & Hemolysin toxin protein RTX & - & 21 & - \\
\hline XF1046 & PD0326 & BamA & $\begin{array}{l}\text { Outer membrane protein assembly } \\
\text { factor BamA }\end{array}$ & - & 25 & 28 \\
\hline XF1496 & PD0711 & & Porin & - & 26 & 46 \\
\hline XF1384 & - & PqaA & Alpha/beta-Hydrolases PqaA & - & 57 & 18 \\
\hline XF2551 & PD1934 & & Dipeptidyl aminopeptidase protein 6 & - & 64 & 34 \\
\hline XF1024 & PD0312 & & Membrane lipoprotein & - & - & 25 \\
\hline XF1745 & - & & Alpha/beta-Hydrolases & - & - & 31 \\
\hline
\end{tabular}

${ }^{a}$ Coding sequences (CDSs) in bold have been previously reported as OMV associated in Temecula1 (Nascimento et al. 2016). CVC, citrus variegated chlorosis; PD, Pierce's disease. 
et al. 2015; Matsumoto et al. 2012; Nascimento et al. 2016; Wai et al. 2003; Yun et al. 2017). The sequential centrifugations, in which both pellet and supernatants were carefully removed, certainly have greatly diminished the presence of molecules not associated with OMVs in the final OMV-enriched preparations. However, because no additional purification steps were performed to get highly purified OMVs (Chutkan et al. 2013; Klimentová and Stulik 2015), the proteins and metabolites that we have identified are referred to as potentially associated with OMVs.

Among the set of proteins identified in the OMVs-enriched fractions of Temecula1, 9a5c, and Fb7 strains, we highlight XadA1, a known Temecula1 OMV marker (Ionescu et al. 2014), and the two other afimbrial adhesins (Hsf/XadA2 and XadA3). The presence of adhesins and hemagglutinins among the OMV-associated proteins might be important to modulate attachment of these nanoparticles to surfaces. As previously shown, $X$. fastidiosa OMVs reduce cell attachment to surfaces, such as the xylem vessels, perhaps by competing with cells for attachment sites (Ionescu et al. 2014).

OMVs of the three strains may hold a capacity to secrete and/or internalize specific molecules given that six porins were identified in the OMV proteome. For instance, it has been suggested that antimicrobial-resistant Escherichia coli OMVs might take up $\beta$-lactam antibiotics into their lumens through increased quantity of OmpC, OmpF, and OmpW (Kim et al. 2018). Moreover, porins and enzymes related to benzoate degradation were uniquely found in OMVs prepared from Pseudomonas putida cultured in media containing benzoate as the energy source (Choi et al. 2014). A related point to consider is that the CDS XF2237/PD1283 (TonBdependent receptor) is one of the most abundant proteins in the OMVs of all three strains. TonB-dependent receptors are bacterial outer membrane proteins that bind and transport siderophores as well as vitamin B12, nickel complexes, and carbohydrates (Noinaj et al. 2010).

Unlike closely related pathogens, $X$. fastidiosa lacks the T3SS (Simpson et al. 2000; Van Sluys et al. 2002). Thus, the release of OMVs would be an advantageous strategy for X. fastidiosa cells to deliver virulence effectors without the requirement of direct proximity to target cells. Our findings corroborate previous studies that investigated smaller sets of OMV proteins in $X$. fastidiosa (Ionescu et al. 2014; Matsumoto et al. 2012; Nascimento et al. 2016; Pierce et al. 2014), hence strengthening one of the OMVs multiple functions, which is to carry determinants of virulence. Accordingly, we have found the lipases/esterases LesA (PD1702/XF0357) and LesB (PD1703/XF0358) as OMV-associated proteins in the three strains that we have investigated (Table 1). These enzymes have been previously described as soluble secreted proteins associated with OMVs and have a relevant role in the virulence of the Temecula1 strain (Nascimento et al. 2016). In addition, we also identified the PtrA protease (XF0531/PD0956) in the OMVsenriched fraction of the three strains. This enzyme plays an important role in the control of cell proliferation, biofilm formation, and virulence of strain Temecula1, and deletion of this gene results in a hypervirulence phenotype (Gouran et al. 2016).

Amid the proteins potentially associated with $X$. fastidiosa OMVs, some caught our attention as potential virulence factors that deserve future functional investigation. One is a putative pectin lyase (XF0119/PD0090) that may act in plant cell wall degradation. Enzymes of the pectin lyase family are recognized as virulence factors in phytopathogens (Hugouvieux-Cotte-Pattat et al. 2014), but their function and/or activity remain unknown in X. fastidiosa.

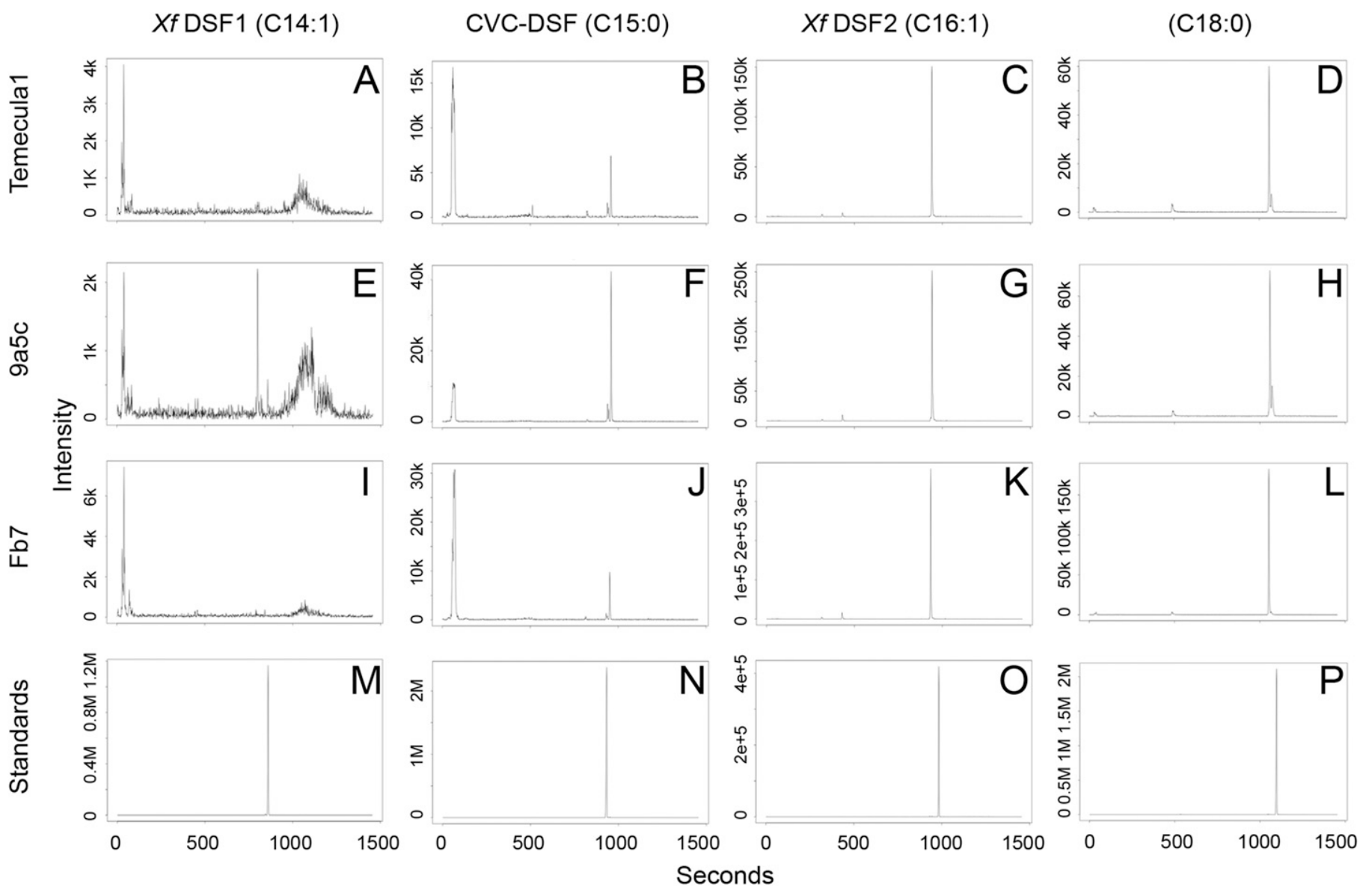

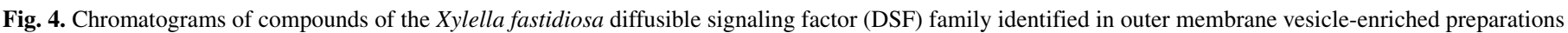

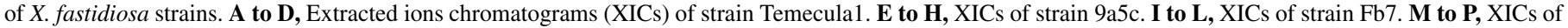
the standards $X$. fastidiosa DSF1, citrus variegated chlorosis (CVC)-DSF, X. fastidiosa DSF2, and C18:0, respectively. 
Another is XF2677/PD2039, which is found in the OMV-enriched fraction of Temecula1 and Fb7 strains. This CDS is annotated as Lascorbate oxidase, which catalyzes the oxidation of ascorbic acid to dehydroascorbic acid. Action of this enzyme could potentially result in depletion of ascorbate produced by the plant host, affecting its primary defense line against external oxidants (Akram et al. 2017).

It is well known that $X$. fastidiosa Temecula1 is capable of producing a range of carboxylic acids with $>12$ carbons, among them the signaling molecules 2 -cis-tetradecenoic acid (X.fastidiosa DSF1) and 2-cis-hexadecenoic acid ( $X$. fastidiosa DSF2) (Beaulieu et al. 2013; Ionescu et al. 2016). Moreover, an additional compound, 12-methyltetradecanoic acid (CVC-DSF), has been shown to be produced by strain 9a5c (Colnaghi Simionato et al. 2007). We have shown that $X$. fastidiosa DSF2 and CVC-DSF, but not $X$. fastidiosa DSF1, were detected among OMVs-associated metabolites in all three strains. Our failure in detecting $X$. fastidiosa DSF1 in $X$. fastidiosa OMVs might be because of its low level of production in the growth condition that we have used. Accordingly, a previous report also failed in detecting $X$. fastidiosa DSF1 in Temecula1 culture supernatants, despite the fact that this molecule was detected on expression of $X$. fastidiosa $\operatorname{RpfF}(X$. fastidiosa DSF synthase) in Pantoea agglomerans as surrogate host (Ionescu et al. 2016). Another explanation of why X. fastidiosa DSF1 (C14:1) was not detected in the OMV-enriched fractions is its relative low hydrophobicity. As such, X. fastidiosa DSF1 does not require OMVs to be carried and instead, diffuses freely to the extracellular environment. Short chain- and medium chain-length DSF species as $X$. fastidiosa DSF1 can be predicted to be sufficiently soluble in water based on their partition coefficient. However, $X$. fastidiosa DSF2 (C16:1) is estimated to have a much lower solubility in water (Ionescu et al. 2016). X. fastidiosa DSF2 can be acquired by cells and subsequently interact with the DSF sensor RpfC (Ionescu et al. 2016). Based on these observations, these authors hypothesized that $X$. fastidiosa DSF2 (and other more hydrophobic DSFs) would interact with hydrophobic matrices, such as bacterial membranes, and perhaps, would be delivered through OMVs. Taking these remarks together, we suggest that $X$. fastidiosa may use OMVs to

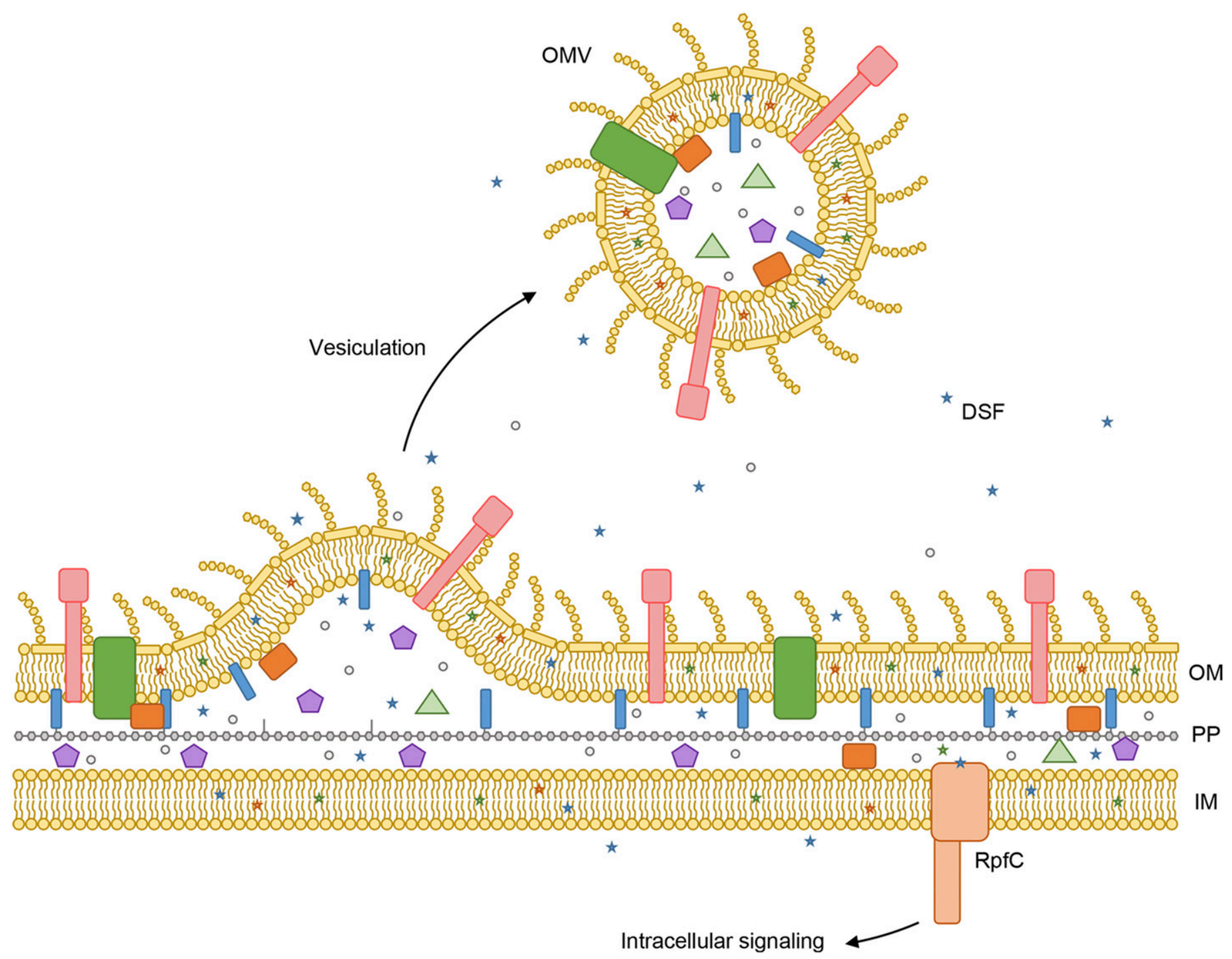

Fig. 5. A simplified model for intercellular signaling mediated by outer membrane vesicles (OMVs) and diffusible signaling factors (DSFs) in Xylella fastidiosa. OMVs are formed at the bacterial cell surface, carrying proteins anchored to the outer membrane (OM) and present in the periplasm (PP), such as proteases, porins, and adhesins, among other functions (represented by geometric forms). Metabolites are also transported, including members of the DSF family (X. fastidiosa DSFs), which are represented by stars of different colors. Although more hydrophobic X. fastidiosa DSFs, such as X. fastidiosa DSF2 (red stars) and citrus variegated chlorosis (CVC)-DSF (green stars), would be enriched to the OMVs, shorter-chain $X$. fastidiosa DSFs, such as $X$. fastidiosa DSF1 (blue stars), would be found predominantly free in the extracellular milieu. The secreted OMVs would deliver $X$. fastidiosa DSF and other compounds to neighboring or distant target cells. Target cells can sense $X$. fastidiosa DSF through the histidine kinase receptor RpfC anchored in the inner membrane (IM), triggering quorum-sensing responses. 
traffic its highly hydrophobic signaling molecules, similar to other bacteria (Brameyer et al. 2018; Li et al. 2016; Mashburn and Whiteley 2005; Morinaga et al. 2018; Toyofuku et al. 2017).

Other than their role in microbial quorum sensing (Mashburn and Whiteley 2005), the hydrophobic signaling molecules transported by OMVs have been suggested to participate in the biogenesis of these vesicles (Mashburn-Warren et al. 2008; Schertzer and Whiteley 2012). For instance, the Pseudomonas aeruginosa signaling molecule 2-heptyl-3-hydroxy-4-quinolone mediates its own insertion into the outer membrane, increasing membrane curvature and leading to the formation of OMVs (Florez et al. 2017; Schwechheimer and Kuehn 2015). Moreover, phospholipid accumulation in the outer leaflet of the outer membrane has been shown to trigger OMV formation and suggested as a general mechanism of OMV biogenesis conserved among Gram-negative bacteria (Roier et al. 2016).

It remains to be investigated if $X$. fastidiosa DSFs would play a role in the biogenesis of $X$. fastidiosa OMVs. It is worth noting that the hypervirulent mutant $\Delta r p f F$ of Temeculal does not produce $X$. fastidiosa DSFs (Ionescu et al. 2016) and overproduces OMVs (Ionescu et al. 2014). Moreover, $\Delta r p f F$ OMVs do not seem to differ from the wild-type strain OMVs, at least regarding their role as antiadhesive nanoparticles and by the presence of the OMV marker protein XadA1 (Ionescu et al. 2014). Thus, future characterization of OMVs produced by the available mutants in the DSF signaling pathway will be a valuable approach to investigate the regulation of OMV biogenesis as well as their role in cell-cell signaling in $X$. fastidiosa.

Based on the current knowledge along with the results described in this work, we suggest that more hydrophobic $X$. fastidiosa DSFs (Ionescu et al. 2016), such as X. fastidiosa DSF2 and CVC-DSF, may be enriched in OMVs, possibly embedded on its lipid bilayer (Fig. 5). Furthermore, $X$. fastidiosa DSF1, a shorter-chain signaling fatty acid (Beaulieu et al. 2013), would be found predominantly free in the extracellular milieu (Fig. 5). Therefore, other than their important functions in host colonization and virulence (Ionescu et al. 2014; Nascimento et al. 2016), X. fastidiosa OMVs would also serve to deliver $X$. fastidiosa DSF2 to neighboring or distant cells. This would activate its receptor $\mathrm{RpfC}$, a histidine kinase of the quorum-sensing signaling pathway (Chatterjee et al. 2008). The strategy of $X$. fastidiosa DSF delivery through OMVs would overcome the limitation of dispersing hydrophobic molecules in an aqueous milieu, such as xylem sap.

\section{ACKNOWLEDGMENTS}

We thank Helvecio Della Coletta-Filho for providing the Fb7 strain; Pio Colepicolo Neto (Instituto de Química, Universidade de São Paulo) for granting us access to the Shimadzu/Bruker GC/MS equipment; and Brett Phinney (University of California, Davis Proteomic Core).

\section{LITERATURE CITED}

Akram, N. A., et al. 2017. Ascorbic acid-A potential oxidant scavenger and its role in plant development and abiotic stress tolerance. Front. Plant Sci. 8: 613.

Almeida, R. P. P., and Nunney, L. 2015. How do plant diseases caused by Xylella fastidiosa Emerge? Plant Dis. 99:1457-1467.

Amano, A., et al. 2010. Outer membrane vesicles function as offensive weapons in host-parasite interactions. Microbes Infect. 12:791-798.

Bahar, O., et al. 2014. The Xanthomonas Ax21 protein is processed by the general secretory system and is secreted in association with outer membrane vesicles. PeerJ 2:ARTN e242.

Bahar, O., et al. 2016. Bacterial outer membrane vesicles induce plant immune responses. Mol. Plant-Microbe Interact. 29:374-384.

Beaulieu, E. D., et al. 2013. Characterization of a diffusible signaling factor from Xylella fastidiosa. MBio 4:e00539-12.

Bendtsen, J. D., et al. 2005. Non-classical protein secretion in bacteria. BMC Microbiol. 5:ARTN 58.

Brameyer, S., et al. 2018. Outer membrane vesicles facilitate trafficking of the hydrophobic signaling molecule CAI-1 between Vibrio harveyi cells. J. Bacteriol. 200:e0740-17.
Burbank, L. P., and Van Horn, C. R. 2017. Conjugative plasmid transfer in Xylella fastidiosa is dependent on tra and trb operon functions. J. Bacteriol. 199:e00388-17.

Büttner, D. 2016. Behind the lines-actions of bacterial type III effector proteins in plant cells. FEMS Microbiol. Rev. 40:894-937.

Cariddi, C., et al. 2014. Isolation of a Xylella fastidiosa strain infecting olive and oleander in Apulia, Italy. J. Plant Pathol. 96:425-429.

Caserta, R., et al. 2010. Expression of Xylella fastidiosa fimbrial and afimbrial proteins during biofilm formation. Appl. Environ. Microbiol. 76:4250-4259.

Chan, K. W., et al. 2017. Antibiotics and iron-limiting conditions and their effect on the production and composition of outer membrane vesicles secreted from clinical isolates of extraintestinal pathogenic E. coli. Proteomics Clin. Appl. 11:1600091.

Chatterjee, S., et al. 2008. Living in two worlds: The plant and insect lifestyles of Xylella fastidiosa. Annu. Rev. Phytopathol. 46:243-271.

Choi, C. W., et al. 2014. Proteomic characterization of the outer membrane vesicle of Pseudomonas putida KT2440. J. Proteome Res. 13:4298-4309.

Chowdhury, C., and Jagannadham, M. V. 2013. Virulence factors are released in association with outer membrane vesicles of Pseudomonas syringae pv. tomato T1 during normal growth. Biochim. Biophys. Acta Proteins Proteomics 1834:231-239.

Chutkan, H., et al. 2013. Quantitative and qualitative preparations of bacterial outer membrane vesicles. Methods Mol. Biol. 966:259-272.

Colnaghi Simionato, A. V., et al. 2007. Characterization of a putative Xylella fastidiosa diffusible signal factor by HRGC-EI-MS. J. Mass Spectrom. 42: 490-496.

da Silva, V. S., et al. 2007. Comparative genomic characterization of citrusassociated Xylella fastidiosa strains. BMC Genomics 8:474.

Davis, M. J., et al. 1981. Axenic culture of the bacteria associated with phony disease of peach and plum leaf scald. Curr. Microbiol. 6:309-314.

Della Coletta, H., et al. 2016. First report of olive leaf scorch in Brazil, associated with Xylella fastidiosa subsp. pauca. Phytopathol. Mediterr. 55: $130-135$

Florez, C., et al. 2017. Membrane distribution of the pseudomonas quinolone signal modulates outer membrane vesicle production in Pseudomonas aeruginosa. MBio 8:e1034-17.

Fulsundar, S., et al. 2014. Gene transfer potential of outer membrane vesicles of Acinetobacter baylyi and effects of stress on vesiculation. Appl. Environ. Microbiol. 80:3469-3483.

Gasperini, G., et al. 2018. Outer membrane vesicles (OMV)-based and proteomics-driven antigen selection identifies novel factors contributing to bordetella pertussis adhesion to epithelial cells. Mol. Cell. Proteomics 17: 205-215.

Gouran, H., et al. 2016. The secreted protease PrtA controls cell growth, biofilm formation and pathogenicity in Xylella fastidiosa. Sci. Rep. 6: 31098.

Grull, M. P., et al. 2018. Small extracellular particles with big potential for horizontal gene transfer: Membrane vesicles and gene transfer agents. FEMS Microbiol. Lett. 365:fny192.

Guerrero-Mandujano, A., et al. 2017. The outer membrane vesicles: Secretion system type zero. Traffic 18:425-432.

Hopkins, D. L., and Purcell, A. H. 2002. Xylella fastidiosa: Cause of Pierce's disease of grapevine and other emergent diseases. Plant Dis. 86:10561066.

Hugouvieux-Cotte-Pattat, N., et al. 2014. Bacterial pectate lyases, structural and functional diversity. Environ. Microbiol. Rep. 6:427-440.

Ionescu, M., et al. 2013. Diffusible signal factor (DSF) synthase RpfF of Xylella fastidiosa is a multifunction protein also required for response to DSF. J. Bacteriol. 195:5273-5284.

Ionescu, M., et al. 2014. Xylella fastidiosa outer membrane vesicles modulate plant colonization by blocking attachment to surfaces. Proc. Natl. Acad. Sci. USA 111:E3910-E3918.

Ionescu, M., et al. 2016. Promiscuous diffusible signal factor production and responsiveness of the Xylella fastidiosa Rpf system. MBio 7:e01054-16.

Jan, A. T. 2017. Outer membrane vesicles (OMVs) of gram-negative bacteria: A perspective update. Front. Microbiol. 8:1053.

Janse, J. D., and Obradovic, A. 2010. Xylella fastidiosa: Its biology, diagnosis, control and risks. J. Plant Pathol. 92:S35-S48.

Kadurugamuwa, J. L., and Beveridge, T. J. 1996. Bacteriolytic effect of membrane vesicles from Pseudomonas aeruginosa on other bacteria including pathogens: Conceptually new antibiotics. J. Bacteriol. 178: 2767-2774.

Kaparakis-Liaskos, M., and Ferrero, R. L. 2015. Immune modulation by bacterial outer membrane vesicles. Nat. Rev. Immunol. 15:375-387.

Katsir, L., and Bahar, O. 2017. Bacterial outer membrane vesicles at the plantpathogen interface. PLoS Pathog 13:ARTN e1006306.

Kim, S. W., et al. 2018. Outer membrane vesicles from beta-lactam-resistant Escherichia coli enable the survival of beta-lactam susceptible E. coli in the presence of beta-lactam antibiotics. Sci. Rep. 8:ARTN 5402. 
Klimentová, J., and Stulik, J. 2015. Methods of isolation and purification of outer membrane vesicles from gram-negative bacteria. Microbiol. Res. 170: 1-9.

Kulp, A., and Kuehn, M. J. 2010. Biological functions and biogenesis of secreted bacterial outer membrane vesicles. Annu. Rev. Microbiol. 64: 163-184.

Kulp, A. J., et al. 2015. Genome-wide assessment of outer membrane vesicle production in Escherichia coli. PLoS One 10:ARTN e0139200.

$\mathrm{Li}$, J., et al. 2016. Outer membrane vesicles containing signalling molecules and active hydrolytic enzymes released by a coral pathogen Vibrio shilonii AK1. Environ. Microbiol. 18:3850-3866.

Li, W. B., et al. 1999. A triply cloned strain of Xylella fastidiosa multiplies and induces symptoms of citrus variegated chlorosis in sweet orange. Curr. Microbiol. 39:106-108.

Lynch, J. B., and Alegado, R. A. 2017. Spheres of hope, packets of doom: The good and bad of outer membrane vesicles in interspecies and ecological dynamics. J. Bacteriol. 199:e00012-17.

Manning, A. J., and Kuehn, M. J. 2011. Contribution of bacterial outer membrane vesicles to innate bacterial defense. BMC Microbiol. 11:258.

Mantri, C. K., et al. 2015. Fimbriae-mediated outer membrane vesicle production and invasion of Porphyromonas gingivalis. MicrobiologyOpen 4: 53-65.

Marques, M. V., et al. 2001. Genetic organization of plasmid pXF51 from the plant pathogen Xylella fastidiosa. Plasmid 45:184-199.

Mashburn, L. M., and Whiteley, M. 2005. Membrane vesicles traffic signals and facilitate group activities in a prokaryote. Nature 437:422-425.

Mashburn-Warren, L., et al. 2008. Interaction of quorum signals with outer membrane lipids: Insights into prokaryotic membrane vesicle formation. Mol. Microbiol. 69:491-502.

Matsumoto, A., et al. 2012. XatA, an AT-1 autotransporter important for the virulence of Xylella fastidiosa Temecula1. MicrobiologyOpen 1:33-45.

Morinaga, K., et al. 2018. Paracoccus denitrificans can utilize various longchain $\mathrm{N}$-acyl homoserine lactones and sequester them in membrane vesicles. Environ. Microbiol. Rep. 10:651-654.

Nascimento, R., et al. 2016. The type II secreted lipase/esterase LesA is a key virulence factor required for Xylella fastidiosa pathogenesis in grapevines. Sci. Rep. 6:18598.

Newman, K. L., et al. 2003. Use of a green fluorescent strain for analysis of Xylella fastidiosa colonization of Vitis vinifera. Appl. Environ. Microbiol. 69:7319-7327.

Newman, K. L., et al. 2004. Cell-cell signaling controls Xylella fastidiosa interactions with both insects and plants. Proc. Natl. Acad. Sci. USA 101: 1737-1742.

Noinaj, N., et al. 2010. TonB-dependent transporters: Regulation, structure, and function. Annu. Rev. Microbiol. 64:43-60.

Pathirana, R. D., and Kaparakis-Liaskos, M. 2016. Bacterial membrane vesicles: Biogenesis, immune regulation and pathogenesis. Cell. Microbiol. 18: 1518-1524.

Petersen, T. N., et al. 2011. SignalP 4.0: Discriminating signal peptides from transmembrane regions. Nat. Methods 8:785-786.
Pierce, B. K., et al. 2014. The Xylella fastidiosa PD1063 protein is secreted in association with outer membrane vesicles. PLoS One 9:ARTN e113504.

Rapicavoli, J., et al. 2018. Xylella fastidiosa: An examination of a re-emerging plant pathogen. Mol. Plant Pathol. 19:786-800.

Redak, R. A., et al. 2004. The biology of xylem fluid-feeding insect vectors of Xylella fastidiosa and their relation to disease epidemiology. Annu. Rev. Entomol. 49:243-270.

Reddy, J. D., et al. 2007. ToIC is required for pathogenicity of Xylella fastidiosa in Vitis vinifera grapevines. Mol Plant-Microbe Interact. 20:403-410.

Roier, S., et al. 2016. A novel mechanism for the biogenesis of outer membrane vesicles in Gram-negative bacteria. Nat. Commun. 7:10515.

Schertzer, J. W., and Whiteley, M. 2012. A bilayer-couple model of bacterial outer membrane vesicle biogenesis. MBio 3:e00297-11.

Schwechheimer, C., and Kuehn, M. J. 2015. Outer-membrane vesicles from Gram-negative bacteria: Biogenesis and functions. Nat. Rev. Microbiol. 13: 605-619.

Sicard, A., et al. 2018. Xylella fastidiosa: Insights into an emerging plant pathogen. Annu. Rev. Phytopathol. 56:181-202.

Sidhu, V. K., et al. 2008. Analysis of outer membrane vesicle associated proteins isolated from the plant pathogenic bacterium Xanthomonas campestris pv. campestris. BMC Microbiol. 8:87.

Silva, R. R., et al. 2014. ProbMetab: An R package for Bayesian probabilistic annotation of LC-MS-based metabolomics. Bioinformatics 30:1336-1337.

Simpson, A. J., et al. 2000. The genome sequence of the plant pathogen Xylella fastidiosa. Nature 406:151-157.

Solé, M., et al. 2015. Xanthomonas campestris pv. vesicatoria secretes proteases and xylanases via the Xps type II secretion system and outer membrane vesicles. J. Bacteriol. 197:2879-2893.

Toyofuku, M., et al. 2017. Membrane vesicle-mediated bacterial communication. ISME J. 11:1504-1509.

Toyofuku, M., et al. 2019. Types and origins of bacterial membrane vesicles. Nat. Rev. Microbiol. 17:13-24.

Turner, L., et al. 2018. Helicobacter pylori outer membrane vesicle size determines their mechanisms of host cell entry and protein content. Front. Immunol. 9:1466.

Van Sluys, M. A., et al. 2002. Comparative genomic analysis of plantassociated bacteria. Annu. Rev. Phytopathol. 40:169-189.

Van Sluys, M. A., et al. 2003. Comparative analyses of the complete genome sequences of Pierce's disease and citrus variegated chlorosis strains of Xylella fastidiosa. J. Bacteriol. 185:1018-1026.

Volgers, C., et al. 2018. Gram-negative bacterial membrane vesicle release in response to the host-environment: Different threats, same trick? Crit. Rev. Microbiol. 44:258-273.

Wai, S. N., et al. 2003. Vesicle-mediated export and assembly of pore-forming oligomers of the enterobacterial ClyA cytotoxin. Cell 115:25-35.

Wang, N., et al. 2012. RpfF-dependent regulon of Xylella fastidiosa. Phytopathology 102:1045-1053.

Yun, S. H., et al. 2017. Proteomic characterization of the outer membrane vesicle of the halophilic marine bacterium Novosphingobium pentaromativorans US6-1. J. Microbiol. 55:56-62. 